\title{
Subarachnoid neurocysticercosis and an intracranial infectious aneurysm: case report
}

\author{
Eduardo Vieira, MD, Igor V. Faquini, MD, Jose L. Silva Jr., MD, Maria F. L. Griz, MD, \\ Auricélio B. Cezar Jr., MD, Nivaldo S. Almeida, MD, and \\ Hildo R. C. Azevedo-Filho, MD, PhD, MSc, FRCS(SN)
}

Department of Neurological Surgery, Hospital Da Restauração, Recife, Brazil

\begin{abstract}
Infectious intracranial aneurysms (IIAs) represent $2 \%-6 \%$ of all intracranial aneurysms and, classically, have been associated with bacterial or fungal agents. The authors report the case of a 42-year-old woman who presented with a typical history of subarachnoid hemorrhage. Digital subtraction angiography (DSA) showed an aneurysmal dilatation on the frontal $\mathrm{M}_{2}$ segment of the left middle cerebral artery (MCA). The patient was treated surgically, and multiple cysts were found in the left carotid and sylvian cisterns, associated with a dense inflammatory exudate that involved the MCA. The cysts were removed, and a fusiform aneurysmal dilatation was identified. The lesion was not amenable to direct clipping, so the authors wrapped it. Histopathological analysis of the removed cysts revealed the typical pattern of subarachnoid neurocysticercosis. The patient received cysticidal therapy with albendazole and corticosteroids, and she recovered uneventfully. Follow-up DSA performed 6 months after surgery showed complete resolution of the aneurysm. The authors performed a review of the literature and believe that there is sufficient evidence to affirm that the subarachnoid form of neurocysticercosis may lead to the development of an IIA and that Taenia solium should be listed among the possible etiological agents of IIAs, along with bacterial and fungal agents.
\end{abstract}

https://thejns.org/doi/abs/10.3171/2019.5.FOCUS19280

KEYWORDS subarachnoid hemorrhage; infectious intracranial aneurysm; neurocysticercosis; stroke

$\mathrm{N}$ EUROCYSTICERCOSIS (NCC) is a pleomorphic disease caused by the penetration of Taenia solium larvae into the central nervous system. It is an endemic disease in several countries in Latin America, Africa, and Asia and, in recent decades, has been increasingly diagnosed in developed countries due to immigration from endemic areas. ${ }^{22} \mathrm{NCC}$ has two main forms: the parenchymal one, which is the most common form and is usually associated with the two most frequent clinical manifestations of the disease-i.e., epilepsy and headache-and the subarachnoid form, which is usually associated with chronic cysticercosis meningitis and causes the most severe clinical manifestations of the disease, such as intracranial hypertension, hydrocephalus, and vascular events. We present the case of a woman with subarachnoid hemorrhage $(\mathrm{SAH})$ due to an infectious intracranial aneurysm (IIA) related to the subarachnoid form of NCC (SNCC) and review the literature on the subject.

\section{Case Report}

A 42-year-old woman presented with a sudden-onset headache associated with vomiting. At admission, she had a Glasgow Coma Scale score of 15 without focal deficits, but she did have significant neck stiffness (Hunt and Hess grade II). CT scanning showed an SAH restricted to the left sylvian fissure (Fig. 1 upper). Due to the typical presentation of aneurysmal SAH, MRI was not performed. Digital subtraction angiography (DSA) showed an aneurysmal dilatation on the frontal $\mathrm{M}_{2}$ segment of the left middle cerebral artery (MCA) associated with multiple areas of irregular caliber that corresponded to an arterial spasm (Fig. 1 lower). The patient underwent surgery via a left pterional craniotomy. After performing a wide microsurgical dissection of the sylvian fissure, we found multiple cysts in the left carotid and sylvian cisterns associated with a dense inflammatory exudate that involved the MCA (Fig. 2 upper). The cysts were removed and further dissection showed spasm of the $\mathrm{M}_{2}$ and $\mathrm{M}_{3}$ segments with the presence of a fusiform dilatation on the frontal $\mathrm{M}_{2}$ segment, which was not amenable to direct clipping (Fig. 2 lower). We then decided to wrap the lesion. Histopathological analysis of the removed cysts showed multiple corrugated membranes and microvilli on the outer

ABBREVIATIONS DSA = digital subtraction angiography; IIA = infectious intracranial aneurysm; MCA = middle cerebral artery; NCC = neurocysticercosis; $\mathrm{SAH}=$ subarachnoid hemorrhage; SNCC = subarachnoid form of NCC.

SUBMITTED April 1, 2019. ACCEPTED May 21, 2019.

INCLUDE WHEN CITING DOI: 10.3171/2019.5.FOCUS19280. 

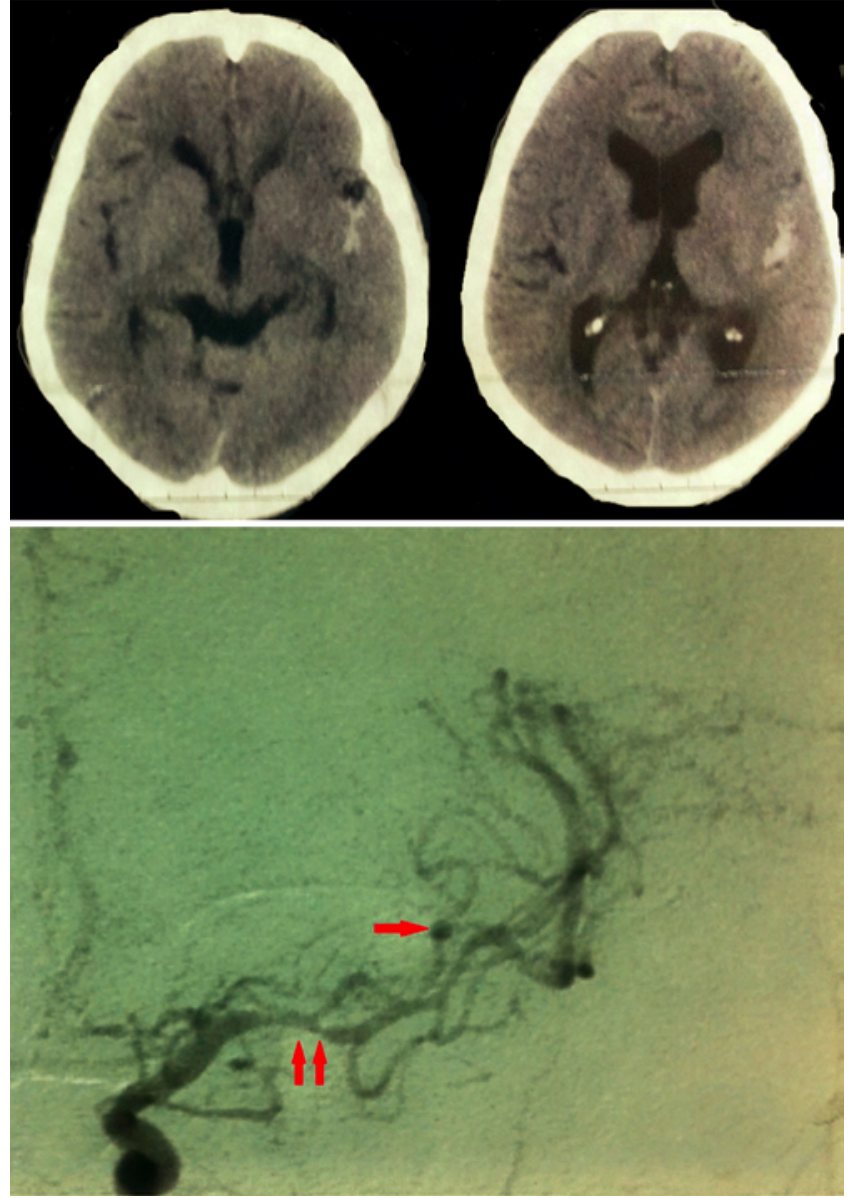

FIG. 1. Upper: CT scans showing SAH confined to the left sylvian fissure. Lower: DSA image showing aneurysmal dilatation affecting the frontal $\mathrm{M}_{2}$ segment of the left MCA (single arrow) associated with multiple areas of irregular caliber corresponding to arterial spasm (double arrows).

surface of the membrane with calcified foci (Fig. 3). No scolex was identified, which is typical in SNCC. After surgery, fundoscopy was performed, and ocular cysticercosis was ruled out. The patient then received cysticidal therapy with albendazole (15 mg/kg/day for 7 days) and corticosteroids (prednisone $1 \mathrm{mg} / \mathrm{kg} /$ day for 3 weeks, starting 3 days prior to the administration of albendazole) and recovered uneventfully. Follow-up DSA, performed 6 months after surgery, showed resolution of the aneurysm and complete regression of irregularities on the vessel caliber (Fig. 4). Forty-eight months after hospital discharge, the patient remains asymptomatic and has fully returned to her routine daily activities.

\section{Discussion}

SNCC occurs less frequently than the parenchymal form, but it is much more severe. ${ }^{7,25}$ The $T$. solium larvae can reach the subarachnoid space through the choroid plexus, traveling throughout the ventricular system, and finally reaching the basal cisterns, or directly through the meningeal vessels. In SNCC, these larvae usually develop into the racemose form of neurocysticercosis, which differs from the cellulosae form found in the parenchymal
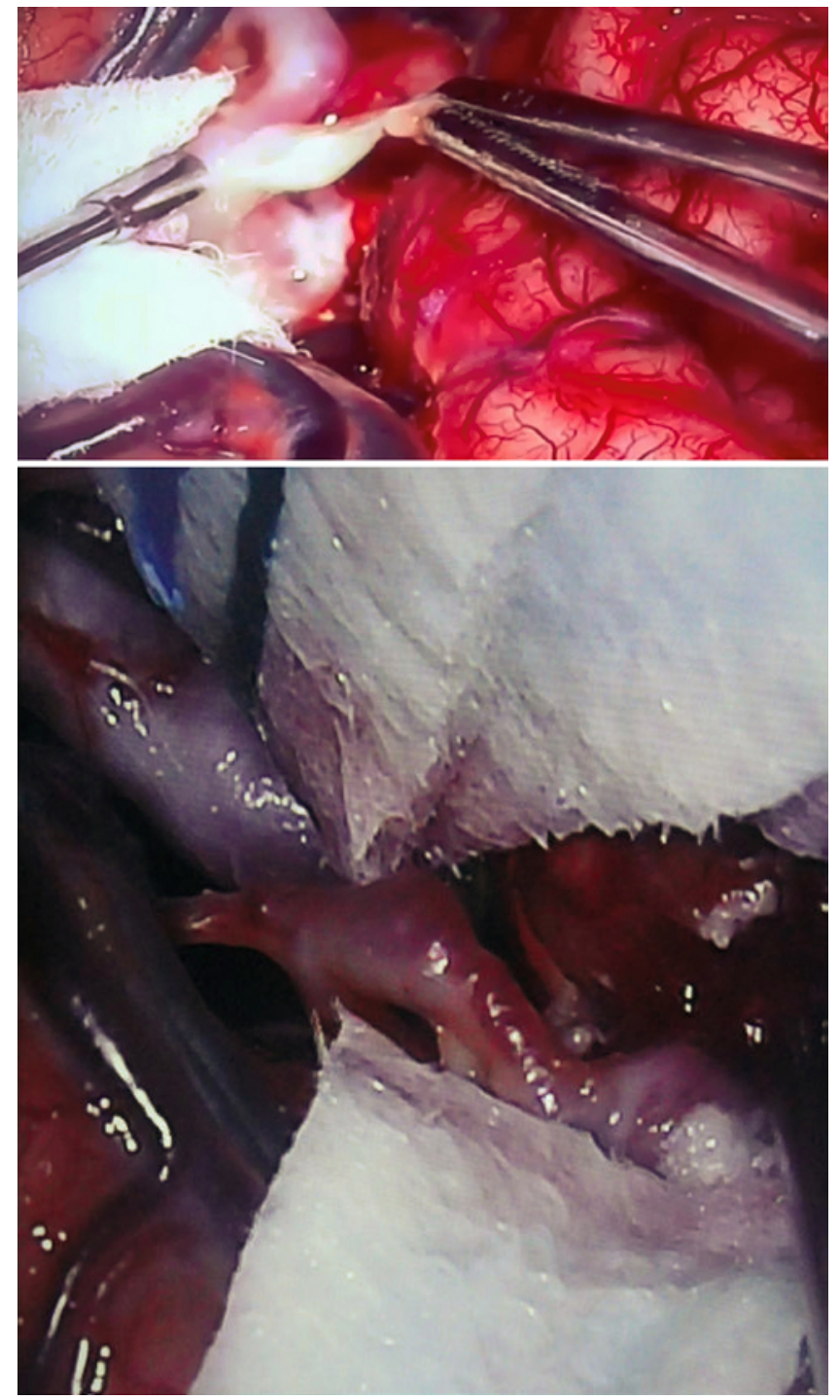

FIG. 2. Wide dissection of the left sylvian fissure revealed a dense exudate (upper) and a fusiform dilatation of the MCA branch (lower).

variant of neurocysticercosis. In the racemose form, the cysts tend to grow to larger diameters than in the cellulosae form (50 vs $10 \mathrm{~mm}$ on average), grouping in clusters that resemble bunches of grapes. ${ }^{7}$ It appears that the larger volume of the cysts in the racemose form is due to the greater existing space in the basal cisterns and to the inflow of CSF into the cyst, contributing to the inability to visualize the scolex in this variant of the disease. A hallmark of SNCC and the racemose form is the strong inflammatory reaction caused by the presence of cysts in the subarachnoid space, leading to a dense exudate composed of lymphocytes, eosinophils, giant cells, collagen fibers, and hyalinized parasitic membranes, as well as high CSF levels of cytokines interleukin-1, -5 , and -6 and tumor necrosis factor $-\alpha$, which are probably secreted by peripheral lymphocytes and activated microglia. ${ }^{6}$ Such inflammatory reaction, resulting in chronic arachnoiditis, seems to be the key to understanding the clinical events related to SNCC. ${ }^{8}$

Patients with SNCC most often present with hydroceph- 

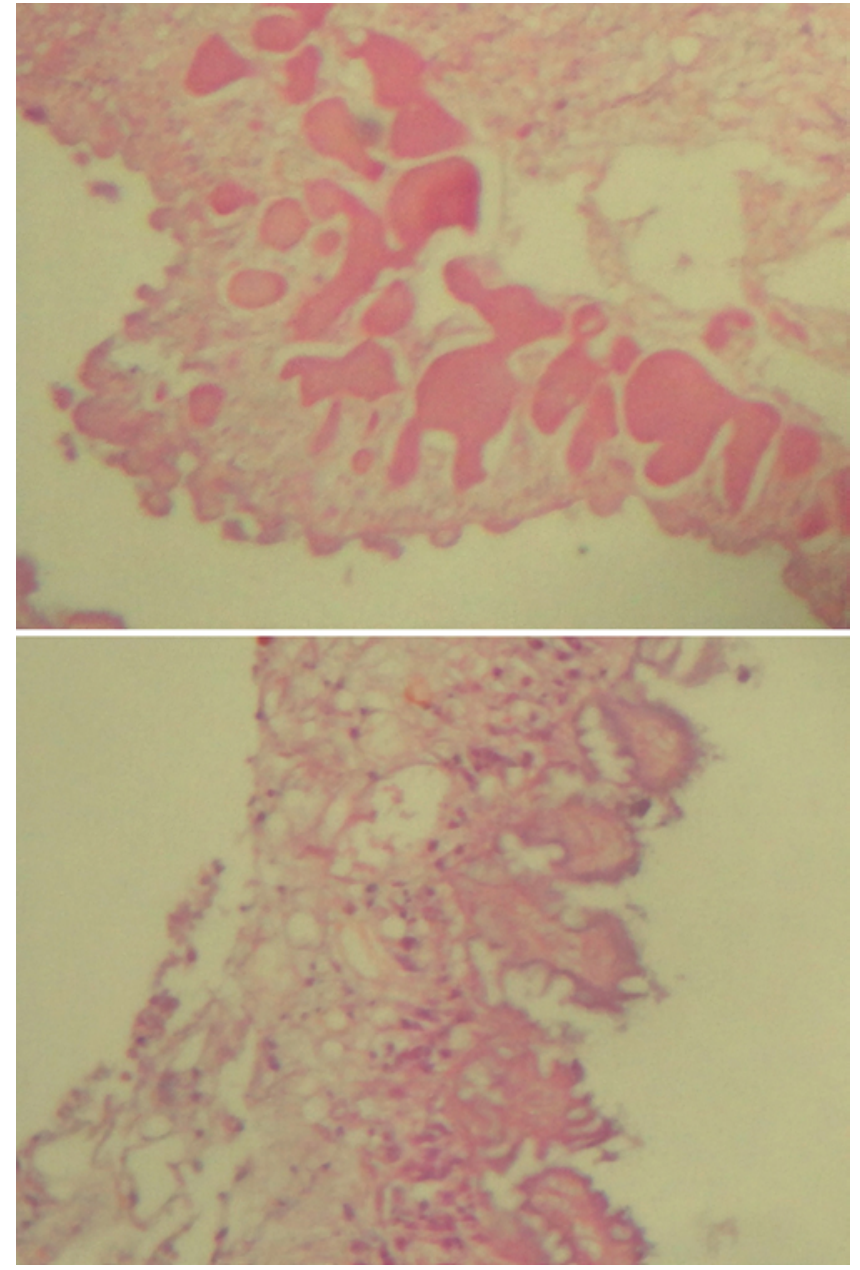

FIG. 3. Upper and lower: Histopathological analysis of the removed cysts. H \& E-stained sections showing multiple corrugated membrane and microvilli on the outer surface of the membrane with calcified foci. No scolex was seen. Original magnification $\times 50$.

alus as well as signs of intracranial hypertension, which occurs due to obstruction of the basal CSF pathways and arachnoid granulations. This obstruction is caused both by the presence of the cysticerci and the associated inflammatory reaction. Another possible presentation is cranial nerve neuropathy, caused by inflammatory arachnoiditis and/or direct compression by a racemose cyst.?

Vascular events are unusual manifestations of SNCC and occur in only $3 \%-12 \%$ of cases of NCC.,10 In most cases, these events are ischemic strokes involving perforating arteries and leading to lacunar infarcts, but they may also affect larger arteries, such as the MCA, and lead to extensive infarctions. ${ }^{16,20,21}$ Hemorrhagic presentation is rare, with few reports in the literature. Inflammation and chronic arachnoiditis affecting the artery wall may lead to occlusive endarteritis, causing ischemic strokes, or weakening of the vessel wall and the formation of aneurysms and bleeding. ${ }^{24}$ In a study by Barinagarrementeria and Cantú, patients with SNCC underwent DSA that showed radiological signs of arteritis in $58 \%$ of cases, which more frequently involved the MCAs and posterior cerebral arteries. $^{2}$

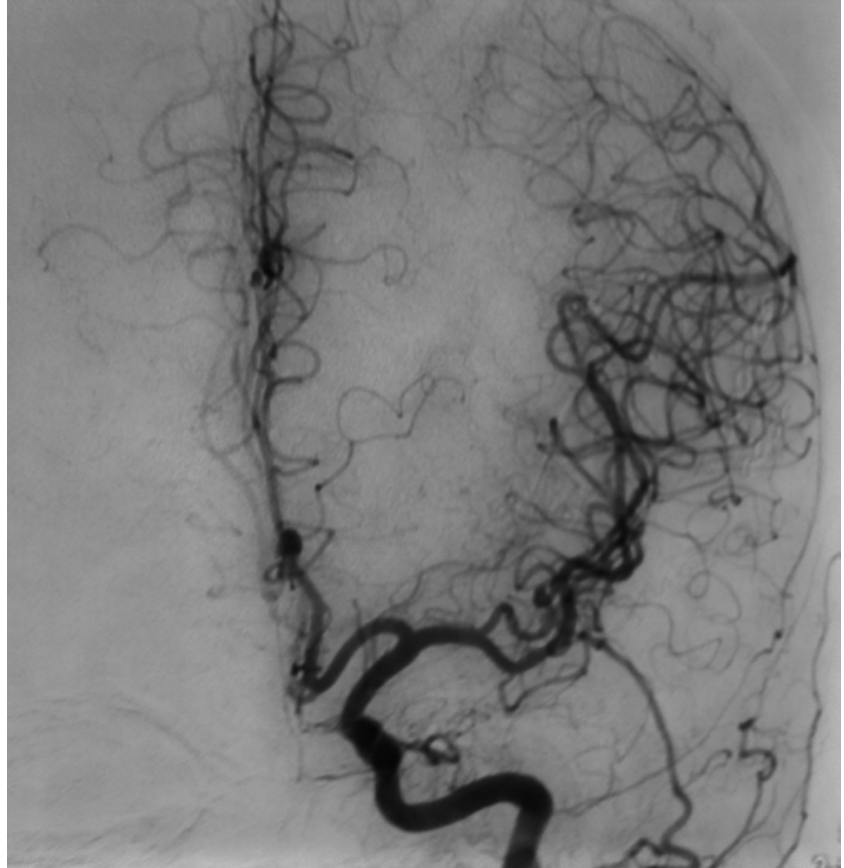

FIG. 4. Follow-up DSA image acquired 6 months after treatment revealing resolution of the aneurysm and complete regression of irregularities on the vessel caliber.

\section{Infectious Intracranial Aneurysms and SNCC}

In 1869, Church was the first to report the occurrence of an IIA in a 13-year-old boy with bacterial endocarditis. ${ }^{9}$ Osler coined the term "mycotic aneurysm" when he described an aortic aneurysm in a patient with bacterial endocarditis, due to the appearance of "fresh fungus vegetations." 19 It is known, however, that most mycotic aneurysms are actually of bacterial origin. A change in the nomenclature was then proposed and the term "infectious (or infected) aneurysm" replaced mycotic aneurysm. ${ }^{3}$

IIAs represent approximately $2 \%-6 \%$ of all intracranial aneurysms, and, in children, it may represent as many as $10 \%{ }^{15,26}$ The etiological agent in most cases is bacteria. A fungal etiology is commonly associated with congenital or acquired immunodeficiency states. The pathophysiological mechanism of IIA formation may be by intravascular or extravascular spread. Intravascular spread occurs through septic emboli that are commonly of cardiac origin. In such cases, the infectious aneurysm tends to occur more distally, usually on the MCA. In contrast, IIAs formed by extravascular spread result from vessel-wall injury and weakening due to the extension of contiguous infectious foci; they usually affect larger-caliber arteries of the cranial base and lead to the formation of more proximal aneurysms compared to those of intravascular etiology. IIAs of bacterial etiology are usually formed by intravascular spread, whereas those of fungal etiology tend to form from extravascular mechanisms. ${ }^{18}$

To the best of our knowledge, there are 8 case reports in the medical literature describing the occurrence of SAH secondary to aneurysms related to SNCC (Table 1). In all of the cases in which surgery was performed, a dense inflammatory reaction/infiltrate was noted along with the 
TABLE 1. Summary of cases of aneurysmal SAH due to NCC-related IIA in the literature

\begin{tabular}{|c|c|c|c|c|c|c|c|c|}
\hline \multirow[b]{2}{*}{ Authors \& Year } & \multirow{2}{*}{$\begin{array}{l}\text { Age (yrs), } \\
\text { Sex }\end{array}$} & \multirow[b]{2}{*}{ Presentation } & \multicolumn{3}{|c|}{ Findings } & \multirow[b]{2}{*}{ Treatment } & \multirow[b]{2}{*}{ HS Findings } & \multirow[b]{2}{*}{ Outcome } \\
\hline & & & DSA & CSF & MRI & & & \\
\hline Zee et al., 1980 & $23, \mathrm{M}$ & $\begin{array}{l}\text { Temporal } \\
\text { hematoma }\end{array}$ & $\begin{array}{l}\text { Distal MCA } \\
\text { aneurysm }\end{array}$ & NA & NA & $\begin{array}{l}\text { Proximal artery } \\
\text { clipping }\end{array}$ & Cysticercus & NA \\
\hline $\begin{array}{l}\text { Soto-Hernandez } \\
\text { et al., } 1996\end{array}$ & $32, \mathrm{M}$ & $\mathrm{SAH}$ & $\begin{array}{l}\text { AICA aneu- } \\
\text { rysm }\end{array}$ & $\begin{array}{l}\text { Cells; protein; glu- } \\
\text { cose + ELISA } \\
\text { for NCC }\end{array}$ & NA & Wrapping & Cysticercus & Improved \\
\hline $\begin{array}{l}\text { Huang et al., } \\
2000\end{array}$ & $32, \mathrm{M}$ & $\mathrm{SAH}$ & $\begin{array}{l}\mathrm{M}_{2} \mathrm{MCA} \\
\text { aneurysm }\end{array}$ & NA & NA & Clipping & Cysticercus & Improved \\
\hline Kim et al., 2005 & $69, \mathrm{M}$ & $\mathrm{SAH}$ & $\begin{array}{c}\text { Proximal MCA } \\
\text { aneurysm }\end{array}$ & NA & NA & Trapping & $\begin{array}{l}\text { Cysticercus \& } \\
\text { aneurysm wall }\end{array}$ & Improved \\
\hline $\begin{array}{l}\text { Marquez-Romero } \\
\text { et al., } 2012\end{array}$ & $38, M$ & $\mathrm{SAH}$ & $\begin{array}{l}\mathrm{M}_{3} \mathrm{MCA} \\
\quad \text { aneurysm }\end{array}$ & Normal & $\begin{array}{l}\text { Multiple T2 hyper- } \\
\text { intense cysts }\end{array}$ & $\begin{array}{l}\text { Conservative } \\
\text { (albendazole } \\
\text { \& steroids) }\end{array}$ & NA & Improved \\
\hline \multirow[t]{2}{*}{$\begin{array}{l}\text { Cárdenas et al., } \\
2012\end{array}$} & $39, F$ & $\mathrm{SAH}$ & $\begin{array}{l}\mathrm{M}_{2} \mathrm{MCA} \\
\text { aneurysm }\end{array}$ & NA & $\begin{array}{l}\text { Cysts in sylvian } \\
\text { fissure }\end{array}$ & Wrapping & Cysticercus & Improved \\
\hline & $33, \mathrm{M}$ & $\mathrm{SAH}$ & $\begin{array}{l}\text { Distal MCA } \\
\text { aneurysm }\end{array}$ & NA & $\begin{array}{l}\text { Cysts in both syl- } \\
\text { vian fissures }\end{array}$ & $\begin{array}{l}\text { Conservative } \\
\text { (albendazole } \\
\text { \& steroids) }\end{array}$ & Cysticercus & Improved \\
\hline Eboli et al., 2012 & $80, \mathrm{M}$ & $\mathrm{SAH}$ & $\begin{array}{l}\text { Distal MCA } \\
\text { aneurysm }\end{array}$ & NA & $\begin{array}{l}\text { Cysts in sylvian } \\
\text { fissure }\end{array}$ & Clipping & Cysticercus & Improved \\
\hline Present case & $42, \mathrm{~F}$ & $\mathrm{SAH}$ & $\begin{array}{l}\mathrm{M}_{2} \mathrm{MCA} \\
\quad \text { aneurysm }\end{array}$ & NA & NA & Wrapping & Cysticercus & Improved \\
\hline
\end{tabular}

$\mathrm{AICA}=$ anterior inferior cerebellar artery; ELISA = enzyme-linked immunosorbent assay; $\mathrm{HS}=$ histopathological study; NA = not available.

presence of many cysticerci surrounding and adhered to the involved vessel, which, in most cases, was the MCA. In addition, the aneurysm was found to be friable and nonsaccular and, in most cases, was treated with alternative methods to direct clipping (i.e., trapping or wrapping). Kim et al. ${ }^{14}$ were the only authors to perform histological analysis of the aneurysm wall; the analysis showed diffuse lymphocytic infiltration and thinning of the vessel wall with no internal elastic lamina, which are common findings in IIAs. Marquez-Romero et al. ${ }^{17}$ and Cárdenas et al. ${ }^{6}$ reported on the conservative treatment of an MCA aneurysm with albendazole and prednisone with good clinical and radiological results, what has also been demonstrated for IIA of other etiologies. We, therefore, believe that there is sufficient evidence that NCC, in its subarachnoid form, through an extravascular inflammatory mechanism affecting the wall of the involved vessel, may lead to the development of an IIA and should be listed among the possible etiological agents, along with bacterial and fungal agents.

There should be a high level of suspicion for IIAs due to SNCC in patients who have parenchymal lesions, but it will be extremely difficult to diagnose in patients who do not have those lesions. The results of CSF analysis may be normal, including negative antigen and antibody tests. Furthermore, intracranial hemorrhage and/or hydrocephalus may make lumbar puncture contraindicated. Radiological diagnosis is also difficult to establish because, in the racemose form, the parasites have a signal intensity identical to that of the CSF, do not show contrast enhancement, and do not have any scoleces. Often, subtle changes such as a unilateral enlargement of a basal cistern will be the only diagnostic clue. ${ }^{11}$ The acquisition of FLAIR se- quences after 5 minutes of continuous inhalation of $100 \%$ supplemental oxygen may have a higher sensitivity for cysticercus visualization. ${ }^{4}$

Although there is report of success with the conservative treatment with albendazole at high doses $(30 \mathrm{mg} /$ $\mathrm{kg} / \mathrm{day}$ ) and corticosteroids (intravenous dexamethasone $24 \mathrm{mg} /$ day, followed by oral prednisone $1 \mathrm{mg} / \mathrm{kg} /$ day), ${ }^{17}$ we do not recommend such an approach. Unlike antibiotic treatment for IIAs from a bacterial or fungal origin, there is doubt about the efficacy of cysticidal drugs for the treatment of SNCC. ${ }^{5}$ In most cases, an aneurysm-securing treatment should be performed. In our review, surgery was performed in 6 of the 8 cases, and we believe this should be the preferred method of treatment because it allows the mechanical removal of the cysts, reducing the inflammatory reaction and also the obstruction of CSF pathways through the basal cisterns. The method of aneurysm treatment during surgery should be evaluated on a case-by-case basis. In only 1 reported case was conventional clipping possible. In the other cases, the aneurysm was treated by trapping or wrapping in conjunction with cysticidal treatment. Depending on the aneurysm location, trapping and extracranial-intracranial or intracranial-intracranial bypass may be an option. After surgical treatment, cysticidal drugs should be administered in all cases. For our patient, as mechanical removal of the cysts was performed, a dosage of $15 \mathrm{mg} / \mathrm{kg} /$ day of albendazole was administered for 7 days along with oral prednisone $(1 \mathrm{mg} / \mathrm{kg} / \mathrm{day})$ for 21 days, starting 3 days prior to albendazole administration. It is important to emphasize that, in all reports, including ours, the outcomes were good, with clinical improvement, which implies, perhaps, a better prognosis of the IIA 
related to SNCC when compared to those of bacterial or fungal origin.

\section{Conclusions}

NCC may present with many clinical manifestations, and, in its subarachnoid form, can lead to the formation of IIAs through an extravascular inflammatory mechanism. The possibility of an IIA due to SNCC should always be considered when a patient with $\mathrm{SAH}$ has associated parenchymal lesions or asymmetrical enlargement of a basal cistern. In our opinion, the treatment of choice is microsurgery, as it allows occlusion of the aneurysm and mechanical removal of racemose cysts, followed by standard drug treatment. Although there are reports of success with the conservative treatment with cysticidal drugs and corticosteroid agents alone, this alternative should be reserved for selected cases associated with high surgical risks and not amenable to endovascular treatment, because there are still doubts about the effectiveness of this type of treatment in SNCC. An SAH due to IIA associated with SNCC seems to have a better prognosis compared with IIA of bacterial or fungal origin.

\section{References}

1. Alarcón F, Hidalgo F, Moncayo J, Viñán I, Dueñas G: Cerebral cysticercosis and stroke. Stroke 23:224-228, 1992

2. Barinagarrementeria F, Cantú C: Frequency of cerebral arteritis in subarachnoid cysticercosis: an angiographic study. Stroke 29:123-125, 1998

3. Bisdas T, Teebken OE: Mycotic or infected aneurysm? Time to change the term. Eur J Vasc Endovasc Surg 41:570-571, 2011

4. Braga F, Rocha AJ, Gomes HR, Filho GH, Silva CJ, Fonseca RB: Noninvasive MR cisternography with fluid-attenuated inversion recovery and $100 \%$ supplemental $\mathrm{O}_{2}$ in the evaluation of neurocysticercosis. AJNR Am J Neuroradiol 25:295-297, 2004

5. Cárdenas G, Carrillo-Mezo R, Jung H, Sciutto E, Hernandez JL, Fleury A: Subarachnoidal neurocysticercosis non-responsive to cysticidal drugs: a case series. BMC Neurol 10:16, 2010

6. Cárdenas G, Guevara-Silva E, Fleury A, Sciutto E, Luis Soto-Hernández J: Subarachnoid hemorrhage in neurocysticercosis: a direct or serendipitous association? Neurologist 18:324-328, 2012

7. Fleury A, Carrillo-Mezo R, Flisser A, Sciutto E, Corona T: Subarachnoid basal neurocysticercosis: a focus on the most severe form of the disease. Expert Rev Anti Infect Ther 9:123-133, 2011

8. Chavarría A, Fleury A, García E, Márquez C, Fragoso G, Sciutto E: Relationship between the clinical heterogeneity of neurocysticercosis and the immune-inflammatory profiles. Clin Immunol 116:271-278, 2005

9. Church WS: Aneurysm of the right cerebral artery in a boy of thirteen. Trans Pathol Soc Lond 20:109-110, 1869

10. Del Brutto OH: Cysticercosis and cerebrovascular disease: a review. J Neurol Neurosurg Psychiatry 55:252-254, 1992

11. do Amaral LL, Ferreira RM, da Rocha AJ, Ferreira NP: Neurocysticercosis: evaluation with advanced magnetic resonance techniques and atypical forms. Top Magn Reson Imaging 16:127-144, 2005

12. Eboli P, Drazin D, Bannykh SI, Schievink W: Surgical management and role of medical therapy in ruptured aneurysmal neurocysticercosis. A case report and review of the literature. Neuroradiol J 25:337-341, 2012
13. Huang PP, Choudhri HF, Jallo G, Miller DC: Inflammatory aneurysm and neurocysticercosis: further evidence for a causal relationship? Case report. Neurosurgery 47:466-468, 2000

14. Kim IY, Kim TS, Lee JH, Lee MC, Lee JK, Jung S: Inflammatory aneurysm due to neurocysticercosis. J Clin Neurosci 12:585-588, 2005

15. Lee KS, Liu SS, Spetzler RF, Rekate HL: Intracranial mycotic aneurysm in an infant: report of a case. Neurosurgery 26:129-133, 1990

16. Levy AS, Lillehei KO, Rubinstein D, Stears JC: Subarachnoid neurocysticercosis with occlusion of the major intracranial arteries: case report. Neurosurgery 36:183-188, 1995

17. Marquez-Romero JM, Santana-López JM, Espinoza-López $\mathrm{DA}$, Zermeño F: Conservative treatment of a ruptured inflammatory infectious aneurysm caused by neurocysticercosis. Clin Neurol Neurosurg 114:810-811, 2012

18. Molinari GF, Smith L, Goldstein MN, Satran R: Pathogenesis of cerebral mycotic aneurysms. Neurology 23:325-332, 1973

19. Osler W: Gulstonian lectures, on malignant endocarditis. Lancet 1:415-418, 1885

20. Rodriguez-Carbajal J, Del Brutto OH, Penagos P, Huebe J, Escobar A: Occlusion of the middle cerebral artery due to cysticercotic angiitis. Stroke 20:1095-1099, 1989

21. Sawhney IM, Singh G, Lekhra OP, Mathuriya SN, Parihar PS, Prabhakar S: Uncommon presentations of neurocysticercosis. J Neurol Sci 154:94-100, 1998

22. Sorvillo FJ, DeGiorgio C, Waterman SH: Deaths from cysticercosis, United States. Emerg Infect Dis 13:230-235, 2007

23. Soto-Hernandez JL, Gomez-Llata Andrade S, Rojas-Echeverri LA, Texeira F, Romero V: Subarachnoid hemorrhage secondary to a ruptured inflammatory aneurysm: a possible manifestation of neurocysticercosis: case report. Neurosurgery 38:197-200, 1996

24. Tellez-Zenteno JF, Negrete-Pulido O, Cantú C, Márquez C, Vega-Boada F, García Ramos G: [Hemorrhagic stroke associated to neurocysticercosis.] Neurologia 18:272-275, 2003 (Spanish)

25. Viola GM, White AC Jr, Serpa JA: Hemorrhagic cerebrovascular events and neurocysticercosis: a case report and review of the literature. Am J Trop Med Hyg 84:402-405, 2011

26. Venkatesan C, Wainwright MS: Pediatric endocarditis and stroke: a single-center retrospective review of seven cases. Pediatr Neurol 38:243-247, 2008

27. Zee CS, Segall HD, Miller C, Tsai FY, Teal JS, Hieshima G, et al: Unusual neuroradiological features of intracranial cysticercosis. Radiology 137:397-407, 1980

\section{Disclosures}

The authors report no conflict of interest concerning the materials or methods used in this study or the findings specified in this paper.

\section{Author Contributions}

Conception and design: Vieira, Faquini, Cezar. Acquisition of data: Vieira, Silva, Cezar. Analysis and interpretation of data: Vieira, Silva, Griz, Cezar. Drafting the article: Vieira, Silva, Griz. Critically revising the article: Vieira, Faquini, Silva, Griz, Almeida, Azevedo-Filho. Reviewed submitted version of manuscript: Vieira, Almeida, Azevedo-Filho. Approved the final version of the manuscript on behalf of all authors: Vieira. Statistical analysis: Azevedo-Filho. Study supervision: Vieira.

\section{Correspondence}

Eduardo Vieira: Hospital da Restauração, Recife, Brazil. evcj2005@gmail.com. 